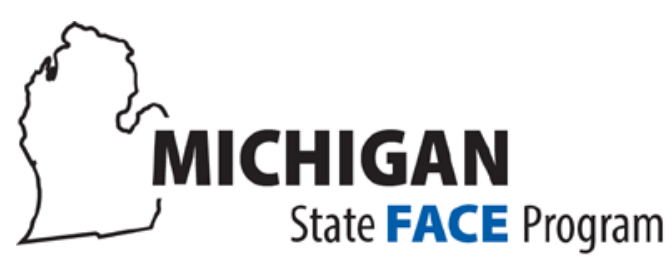

Fatality Assessment \& Control Evaluation

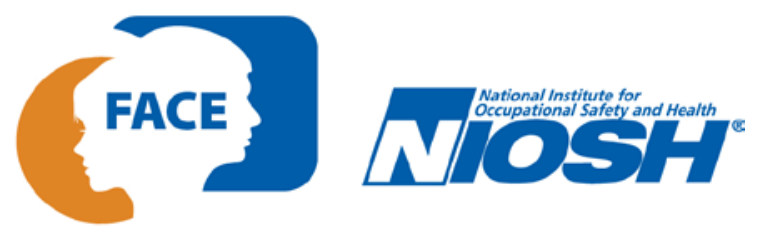

Michigan State University

Department of Medicine - Occupational and Environmental Medicine

909 Fee Road, 117 West Fee Hall • East Lansing, MI 48824 • 1-517-353-1846 • https://oem.msu.edu

INCIDENT HIGHLIGHTS

DATE:

Winter 2015

TIME:

1:30 p.m.

VICTIM:

Farmer in his 70s

INDUSTRY/NAICS CODE:

Agriculture/11

EMPLOYER:

Self-employed

SAFETY \& TRAINING:

On-the-job

SCENE:

Farm Field

LOCATION:

Michigan

- EVENT TYPE:

Machine

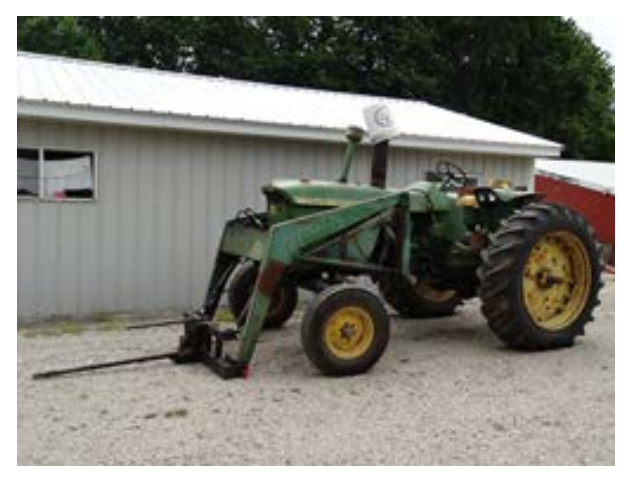

REPORT\#: 15MI066

REPORT DATE: 10/23/18

\title{
Farmer Starting Tractor From Ground Run Over by Tractor
}

\section{SUMMARY}

A male farmer in his 70s died when he was run over by his John Deere 3020 diesel tractor he was starting while standing on the ground. The decedent was planning to move some hay bales to feed the cows. The tractor had been driven into the pole barn and had been left in gear after its last use. When the tractor started, the rear wheel struck the decedent, pulling him under the wheel while the tractor moved forward. Friends who were working near the pole barn heard the decedent call out.... READ THE FULL REPORT> (p.3)

\section{CONTRIBUTING FACTORS}

Key contributing factors identified in this investigation include:

- Decedent was starting the tractor from the ground rather than the seat.

- Improper tractor shut down procedures.

- Tractor condition

- Aging impairment LEARN MORE> (p.7)

\section{RECOMMENDATIONS}

MIFACE investigators concluded that, to help prevent similar occurrences, employers should:

- Start tractors from the operator seat only, not from the ground.

- Follow safe equipment shutdown procedures as described in the operator's manual.

- Recognize the potential human factor limitations associated with aging and take advantage of the organizations and extension services that promote farming safety..... LEARN MORE $>$ (p.7)

https://oem.msu.edu 


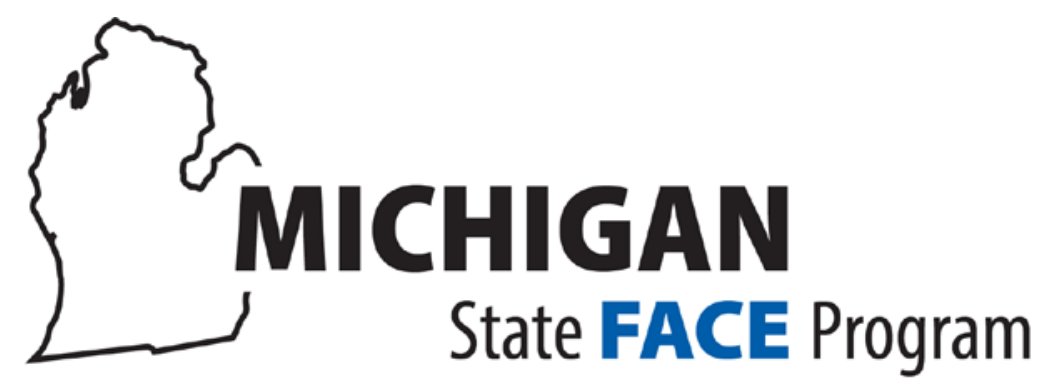

Fatality Assessment \& Control Evaluation

\author{
Michigan State University \\ Department of Medicine - Occupational and Environmental Medicine \\ 909 Fee Road, 117 West Fee Hall • East Lansing, MI 48824 \\ 1-517-353-1846. https://oem.msu.edu
}
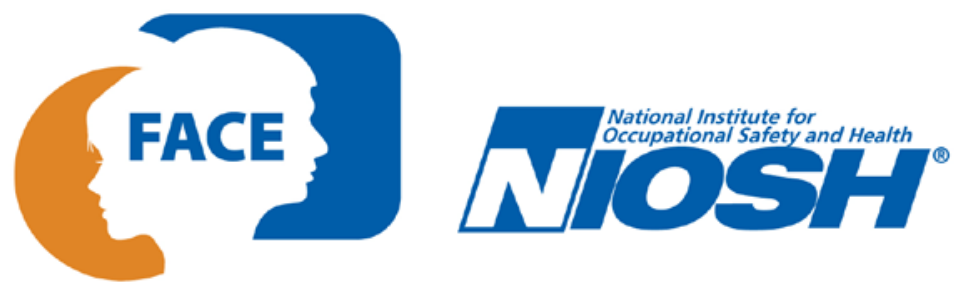

Michigan Fatality Assessment and Control Evaluation (FACE) Program

MIFACE (Michigan Fatality Assessment and Control Evaluation), Michigan State University (MSU) Occupational \& Environmental Medicine, 909 Fee Road, 117 West Fee Hall, East Lansing, Michigan 48824-1315; http://www.oem.msu.edu.

This information is for educational purposes only. This MIFACE report becomes public property upon publication and may be printed verbatim with credit to MSU. Reprinting cannot be used to endorse or advertise a commercial product or company. All rights reserved. MSU is an affirmative-action, equal opportunity employer. 


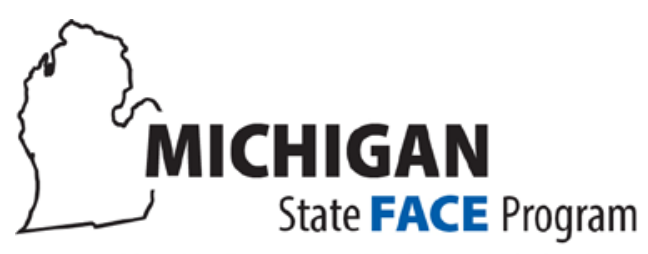

Fatality Assessment \& Control Evaluation

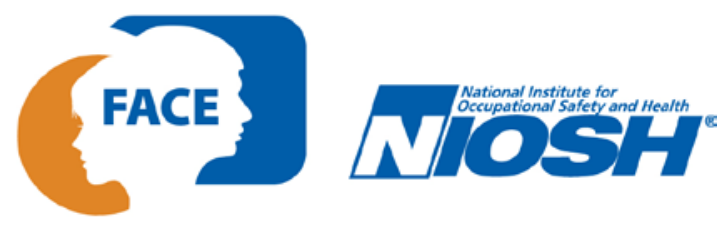

Michigan State University

Department of Medicine - Occupational and Environmental Medicine

909 Fee Road, 117 West Fee Hall • East Lansing, Ml 48824 • 1-517-353-1846 • https://oem.msu.edu

\section{SUMMARY}

A male farmer in his 70s died when he was run over by his John Deere 3020 diesel tractor he was starting while standing on the ground. The decedent was planning to move some hay bales to feed the cows. The tractor had been driven into the pole barn and had been left in gear after its last use. When the tractor started, the rear wheel struck the decedent, pulling him under the wheel while the tractor moved forward. Friends who were working near the pole barn heard the decedent call out. Running to help, they found the tractor's movement stopped by a pole barn wall. One individual turned off the tractor while the other individual called for emergency response. The decedent was declared dead at the scene.

\section{INTRODUCTION}

In Winter 2015 a male farmer in his 70s died when he was run over by a tractor. MIFACE personnel contacted one of the decedent's family members who agreed to meet the MIFACE interviewer at the family home. After the interview, MIFACE personnel were directed to another location to view the tractor involved in the incident. MIFACE reviewed the death certificate, police and medical examiner site investigation reports during the writing of this report. Pictures used in the report are courtesy of the responding police department and those taken at the time of the MIFACE site visit.

\section{EMPLOYERS}

The decedent was the owner of the farm. He raised Hereford and Angus mix cattle and calves; at the time of the incident, he had nine cows, nine calves, nine baby calves, and a bull. He also processed/butchered the cows and sold the meat. He had farmed 80 acres until 2006-2007 when he allowed 55 acres to revert to wetland. He had previously worked at a number of jobs, including butchering meat with his father and working for a packing company as a sausage maker and delivery truck driver.

He spent his summers on farms where he helped and learned "how to farm". In the late 1980s-early 1990s the decedent started farming full time. MIFACE learned he had both hips replaced. As a consequence, the family member indicated "he didn't get on the tractor".

The decedent bought the tractor second-hand approximately 16 years ago. According to his family member, the previous owner had let the tractor sit out in the elements and the decedent had built a pole barn next to the animal barn to protect the tractor. According to the family member, he used the tractor to help move cows from field to field and to transport hay bales to feed them. MIFACE did not see a copy of the tractor manual but was told the decedent had an operator's manual for the tractor.

The family member shared three incidents involving the decedent regarding his work practices, two involving a fall. In one incident, the decedent had texted the family member a couple of weeks prior to the fatal incident to let the family member know that he had not properly set a ladder and the ladder scooted away, causing him to fall from the ladder (injuries sustained not elaborated on by the family member). He fell another time and fractured his kneecap.

The third incident was a near miss involving starting the tractor while standing on the ground. Approximately three weeks prior to the incident, the decedent had done the same thing except the tractor was in reverse. One of his friends helping out at the farm (one of the same friends helping out at the time of the fatal incident) jumped onto the tractor and turned the tractor off. His friend told him to get on the tractor before starting it. 

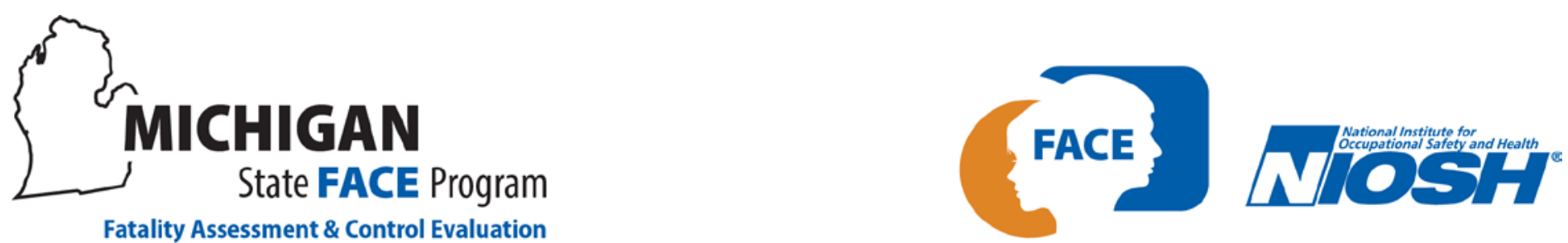

Fatality Assessment \& Control Evaluation

Michigan State University

Department of Medicine $\cdot$ Occupational and Environmental Medicine

909 Fee Road, 117 West Fee Hall • East Lansing, MI 48824 • 1-517-353-1846 • https://oem.msu.edu

\section{WRITTEN SAFETY PROGRAMS and TRAINING}

The decedent did not have a health and safety program for the farm. He did not utilize MSU Extension or other agricultural organization training programs.

\section{WORKER INFORMATION}

The two individuals present and working with the decedent at the time of the incident were family friends. The decedent had an arrangement with these individuals; the decedent furnished hay to them and they would help him with the animals and other farming activities.

\section{INCIDENT SCENE}

The John Deere 3020 tractor had previously been driven into and parked in a pole barn. The tractor was usable, but in overall poor condition (tires, seat, controls, loose sheet metal, handles, etc.) (See Photos 1 and 2). The tractor starter wiring had been modified, including cutting the wire to the clutch safety switch, the cable that controlled shifting would not let the tractor be placed into neutral, and the emergency brakes were frozen.

The step used to access the operator platform was 26 inches above the ground and the operator platform was approximately 40 inches above the ground. The tractor tire was size 14.9-38 and 5 feet tall.

The west side of the pole barn was open to a driveway. The tractor had been driven into the pole barn and the front of the tractor was facing east.

\section{WEATHER}

It was $22^{\circ} \mathrm{F}$, cloudy, with winds from the north-northwest at $10 \mathrm{mph}$. Snow was present on the ground. [Weather Underground].

\section{INVESTIGATION}

The decedent and his two friends (Worker A and Worker B) who were helping him that day, were working with the calves. Worker A and Worker B were putting away gates and were located just south of him in another area of the pole barn. The decedent told the two individuals that he was going to start the tractor up so he could go feed the cattle. The decedent walked over to the tractor. The decedent stood in front of the left rear tire and started the tractor. It is unknown if he reached up to turn the tractor on or "by-pass started" the tractor.

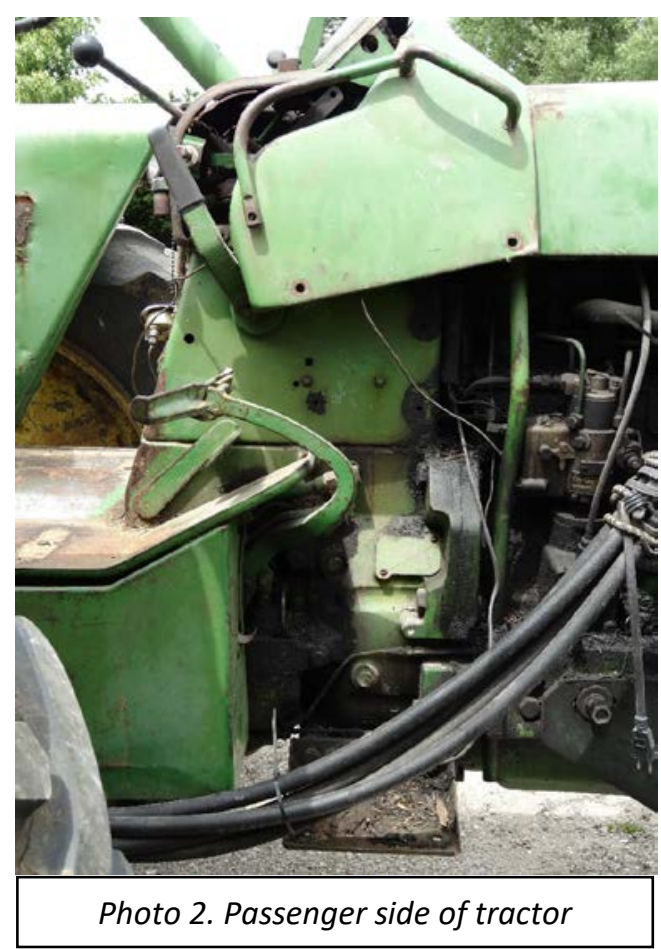




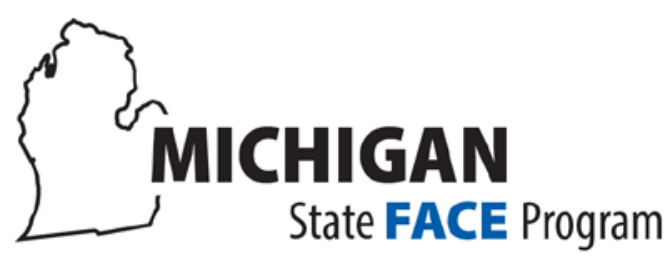

Fatality Assessment \& Control Evaluation

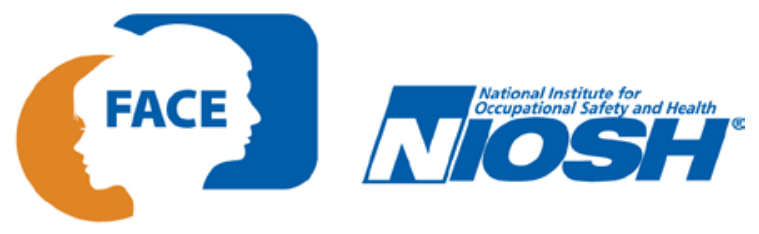

Michigan State University

Department of Medicine - Occupational and Environmental Medicine

909 Fee Road, 117 West Fee Hall • East Lansing, MI 48824 • 1-517-353-1846 • https://oem.msu.edu

The two individuals working with him heard the tractor start up and then they heard the decedent yell. Both individuals ran to see what was going on. Apparently, the tractor was in a forward gear, and when it started, it jumped forward. When they arrived at the incident site, the tractor hay bale forks had penetrated the walls of the pole barn. The pole barn walls stopped the forward motion of the tractor, but the tires kept spinning, running him over just below his waist and sending him out behind the tire.

The individuals found the decedent behind the left rear tire and partially under the tractor. Worker B jumped up to the operator platform and turned the tractor off while Worker A called for emergency response. Worker B held up the decedent's head as it was face down in the dirt until medical personnel arrived.

\section{CAUSE OF DEATH}

The death certificate listed the cause of death as multiple blunt force injuries due to or as a consequence of a pedestriantractor collision. The medical examiner did not perform any tests on the decedent's blood to determine if alcohol, prescription or non-prescription drugs were present.

\section{CONTRIBUTING FACTORS}

Occupational injuries and fatalities are often the result of one or more contributing factors or key events in a larger sequence of events that ultimately result in the injury or fatality. The following hazards were identified as key contributing factors in this incident:

- Decedent was starting the tractor from the ground rather than the seat.

- Improper tractor shut down procedures.

- Tractor in poor condition.

- Possible impairments in the deceased associated with aging.

\section{RECOMMENDATIONS/DISCUSSION}

Recommendation \#1: Start tractors from the operator seat only, not from the ground.

Discussion: A tractor may move suddenly and run over anything in its path if started while in gear. The operator's seat is the only place where an operator can maintain proper control during equipment start-up and during equipment operation. While seated in the operator's seat, an operator should check the engine throttle position, disengage the clutch and shift the transmission into neutral or park before the engine is started. Setting the brakes will prevent the tractor from rolling before the operator engages the transmission. Before starting a tractor engine, the operator should also ensure the power take off is disengaged. Performing these steps will reduce the likelihood of a tractor or machine unexpectedly moving forward or backward after the engine starts. In addition, if a tractor or machine does unexpectedly begin to move after starting, an operator seated in the seat will not be in danger of being run over and will be in position to maintain safe operating control.

Many modern tractor systems are equipped with additional safety interlock systems. Tractors equipped with neutralstart safety switches prevent starting the tractor engine unless the clutch pedal is depressed, the shift lever is in neutral or park or a combination of both. Some tractor models are equipped with a seat safety switch that requires the operator to be in the operator's seat to start the tractor. When using an older model tractor without these safety interlock systems, operators must be particularly careful to follow safe tractor shutdown procedures. 


\section{MICHIGAN}

Fatality Assessment \& Control Evaluation

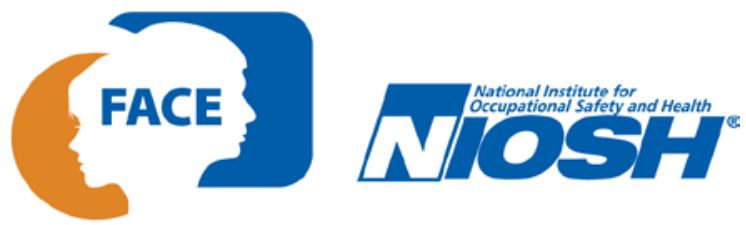

Michigan State University

Department of Medicine - Occupational and Environmental Medicine

909 Fee Road, 117 West Fee Hall • East Lansing, MI 48824 • 1-517-353-1846 • https://oem.msu.edu

Recommendation \#2: Tractor operators should always utilize proper tractor shut-off procedures prior to exiting the tractor seat.

Discussion: Tractor operators should follow safe shut down procedures prior to dismounting the tractor. The decedent, according to his family member, had the John Deere 3020 operator manual, although the family member did not know where it was located. The tractor's operating manual should be followed for any specific instructions. If a tractor owner does not have the operating manual, the owner should request it. For their own safety and that of bystanders, operators should never leave the driver's seat of a tractor that is still running and should properly shut it down before leaving the operator's seat. Before dismounting the tractor, operators should always:

- Disengage the PTO and lower all implements to the ground

- Place all controls in the neutral position

- Place the transmission in park lock, or if a manual transmission, place in the lowest gear

- $\quad$ Set the parking brake(s)

- Stop (turn off) the engine

- Remove the key

Recommendation \#3: Owners/operators should inspect and maintain equipment to ensure it is in good operating condition.

Discussion: Like many farmers, the decedent used the tractor "because it still worked". The tractor, although operable, was not in good condition, and had many safety issues placing any individual operating the tractor at risk. Tractor owners should ensure that any individual, including themselves, conduct a preoperational check of the tractor to ensure that all safety controls are in place and all systems are in good operational condition. A pre-operational checklist, as a minimum, could include these items:

- Check for loose, broken, missing, or damaged parts. Have everything put in good repair.

- Make certain all safety devices are in place.

- Check ROPS and safety belt for damage. (A damaged ROPS or safety belt MUST be replaced).

- Make certain implements and attachments are properly installed and that the tractor and implement PTO RPM ratings match.

- Check the tires for cuts, bulges and correct pressure. Replace worn or damaged tires.

- Check service and parking brakes for proper operation.

- Check the engine oil system. Add oil if required.

- Check the radiator for liquid level.

- Perform all maintenance procedures outlined by the tractor manufacturer (may include radiator, air cleaner, fuel level checks).

- Check that PTO drive locking devices are latched.

- Check that the tractor PTO shield and driveline guarding are in place and operating properly.

- Check the tractor and implement hydraulic system. Have any leaks or damaged parts repaired.

Important to safe equipment use is timely equipment maintenance; the tractor the decedent was using was not maintained according to the manufacturer's requirements. Maintenance can be divided into two types, preventive and corrective. Preventive maintenance can be described as a set of activities to improve the overall reliability and to 


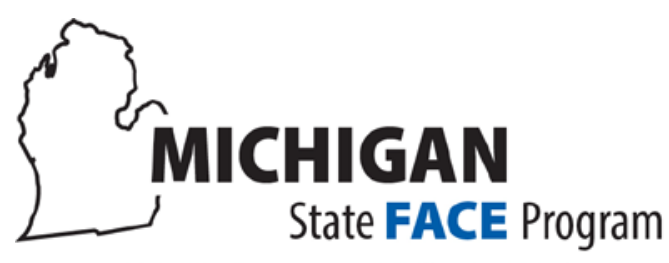

Fatality Assessment \& Control Evaluation

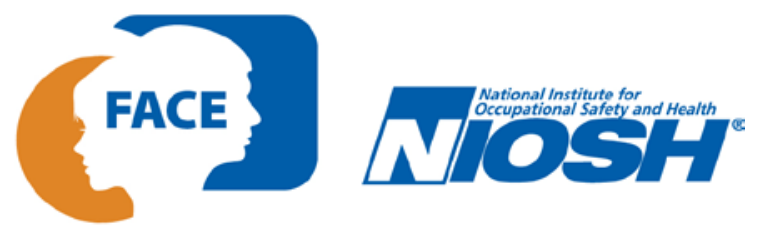

Michigan State University

Department of Medicine - Occupational and Environmental Medicine

909 Fee Road, 117 West Fee Hall • East Lansing, MI 48824 • 1-517-353-1846 • https://oem.msu.edu

prevent failure of the equipment. Corrective maintenance can be described as unscheduled or failure-based equipment maintenance. When servicing equipment, owners/operators or qualified service personnel should follow the recommendations provided in the manufacturer's operator/service manual for the equipment.

Recommendation \#4: Agricultural equipment operators should recognize the potential human factor limitations associated with aging and take advantage of the many organizations and extension services that promote farming safety.

Discussion: Farmers often continue to work on their farms well past "retirement" age. Cognitive and/or functional impairments are often associated with advanced age. Cognitive impairments can affect the following areas: attention, judgment and problem solving, increased reaction time, lapses of consciousness or control, and memory lapses. Functional impairments, including sensory impairments, can affect vision, peripheral sensation of the extremities, strength, flexibility and coordination. Aging impairment was a factor in this incident. Older workers should recognize these limitations and seek help from relatives and/or friends to accomplish a work activity when required.

An organization dedicated to assisting farmers with disabilities and/or impairments is Michigan AgrAbility. Michigan AgrAbility provides direct services to farmers with injuries, illnesses or aging conditions so they can continue the occupation and lifestyle they love. In partnership with Easterseals of Michigan and Michigan State University Extension, Michigan AgrAbility provides help to farmers with chronic health conditions. Michigan AgrAbility's Assistive Technology professional comes to the farm and conducts an assessment. Then the Assistive Technology Professional makes recommendations that may include the use of different tools, modifications to the worksite, procedural changes, or suggestions for alternative agricultural production more suited to the farmer's current capabilities. In this case, the Assistive Technology Professional may have suggested adding steps to the tractor to make it easier for the decedent to access the seat, or a lift to lift him into the tractor operator seat to facilitate the practice of only starting a tractor when in the tractor seat.

His medical impairment caused the decedent to modify his behavior (would not start the tractor from the tractor operator seat) despite the fact that he had recent injuries and near misses while using the tractor. Additionally, many of his habits and behaviors may have been learned when he was younger working on a farm in the summer and from his father. Farmers should take advantage of the many organizations and extension services that promote farming safety, to not only remind themselves of safe work practices, but also educate their young family members in how to identify potential safety and health hazards on the farm and how to prevent injury by using safe work practices.

\section{ADDITIONAL RESOURCES}

- Michigan AgrAbility. http://www.michiganagrability.org/

- MIFACE Investigation Reports

o Farmer Run Over and Pinned Under Tractor Tire. (\#11MI115) https://oem.msu.edu/images/MiFACE/11MI115.pdf

- Farmer Run Over by Tractor or Manure Spreader (\#01MI058) (https://oem.msu.edu/images/MiFACE/01MI058v1.pdf

o Farm Hand Run Over by Tractor While Starting the Tractor While Standing On the Ground (02MI140) https://oem.msu.edu/images/MiFACE/02MI140v1.pdf 


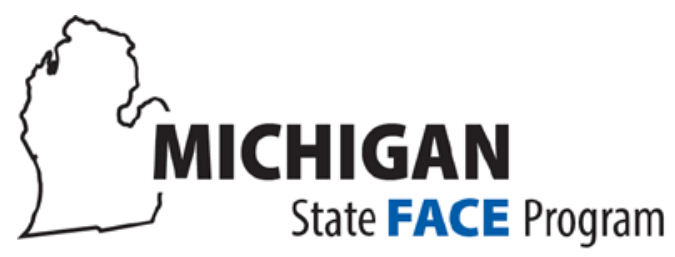

Fatality Assessment \& Control Evaluation

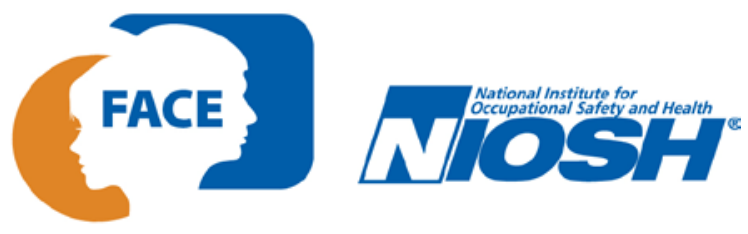

Michigan State University

Department of Medicine - Occupational and Environmental Medicine

909 Fee Road, 117 West Fee Hall • East Lansing, MI 48824 • 1-517-353-1846 • https://oem.msu.edu

- Preventing Machine Hazards. Agricultural Tailgate Safety Training, Ohio State University Extension. http://nasdonline.org/1727/d001716/preventing-machine-hazards.html

- Khodabakhshian, R. A review of maintenance management of tractors and agricultural machinery: preventive maintenance systems. Agricultural Engineering International: CIGR Journal. Vol. 15, No.4, 147-156.

\section{DISCLAIMER}

Mention of any company or product does not constitute endorsement by the Michigan FACE program or the National Institute for Occupational Safety and Health (NIOSH). In addition, citations to websites external to NIOSH do not constitute NIOSH endorsement of the sponsoring organizations or their programs or products. Furthermore, NIOSH is not responsible for the content of these websites. All web addresses referenced in this document were accessible as of the publication date.

\section{ACKNOWLEDGEMEMENT}

The Michigan FACE Program would like to acknowledge the decedent's family members for providing assistance and information for this investigation. 